\title{
ANÁLISE DO CURSO DE ENGENHARIA CIVIL DA UNIVERSIDADE FEDERAL DE OURO PRETO E SUA ADEQUAÇÃO AO MERCADO DE TRABALHO
}

Carolina S. O. Freitas - carolina.freitas@aluno.ufop.edu.br

Universidade Federal de Ouro Preto

Rua Professor Paulo Magalhães Gomes

CEP: 35400-000 - Ouro Preto - Minas Gerais

Chrystian C. Ventura - chrystian.ventura@aluno.ufop.edu.br

Gabriela R. Oliveira - gabriela.rosa1 @ aluno.ufop.edu.br

Gustavo A. F. Cardoso - gustavo.froes@ aluno.ufop.edu.br

Karina M. M.Silva - karina.maciel@ aluno.ufop.edu.br

Resumo: Com o processo de ensino-aprendizagem adquirindo ênfase no mercado de trabalho, buscou-se vislumbrar através de formulários a influência da matriz curricular na atuação do profissional formado, além de fazer um comparativo entre as opiniões de alunos e ex-alunos da instituição, a fim de avaliar qual o grau de satisfação dos mesmos com o modelo de curso oferecido. Este trabalho tem o caráter dissertativo-argumentativo, cujo objetivo é interpretar os dados obtidos e aplicar melhorias ao curso de Engenharia Civil da Universidade Federal de Ouro Preto (UFOP), tais quais, aumento da carga horária prática e atualização das metodologias de ensino.

Palavras-chave: Qualidade de ensino. Engenharia Civil. Discentes. Egressos. Mercado de Trabalho.

\section{INTRODUÇÃO}

Anteriormente ao ano de 2017, em avaliação realizada pelo Instituto Nacional de Estudos e Pesquisas Educacionais Anísio Teixeira (INEP), o curso de Engenharia Civil da UFOP obteve conceito preliminar de curso (CPC) 3 numa escala de 1 a 5, sendo considerado pelo Ministério da Educação (MEC) como nota regular (MEC, 2020). Com isso, discentes de entidades estudantis do curso se reuniram para criar um grupo que ficaria conhecido como Civil Nota 5, visando melhorias na qualidade de ensino, com o objetivo de obter reconhecimento externo em avaliações como o ENADE e satisfação interna por acadêmicos.

Neste contexto, o objetivo deste trabalho é coletar e analisar informações dos discentes e egressos do curso de Engenharia Civil da UFOP quanto ao modelo de ensino do curso. A intenção de tais informações é obter melhorias na estrutura do curso, de forma que os engenheiros formados possuam qualidades favoráveis à sua inserção no mercado de trabalho, e que possa melhorar a satisfação dos alunos atuais no desenvolvimento da sua formação.

Como base para a pesquisa foi utilizado o artigo "Análise do Curso de Engenharia Civil da Universidade Federal de Ouro Preto de Acordo Com a Percepção dos Alunos", desenvolvido anteriormente também pelo Grupo Civil Nota 5. Para a realização desta pesquisa foram utilizadas duas plataformas digitais de formulários, SurveyMonkey em 2017 e Google Forms em 2019. Foram usados, a título de comparação, quatro formulários, sendo estes: formulário do aluno e formulário do ex-aluno, aplicados em 2017, e de igual modo para 
o ano de 2019. Para análise e interpretação desses formulários foram utilizados conceitos de Estatística Descritiva.

\section{ESTRUTURA PEDAGÓGICA DO CURSO}

A matriz curricular de formação do curso de Engenharia Civil da UFOP é datada de 1996, com pequenas modificações ocorridas em 2002 e 2006. Estruturada em 10 semestres, possui uma carga total de 4075 horas, sendo 3735 horas de disciplinas obrigatórias, 180 horas de disciplinas eletivas e 160 horas de outras atividades (ESCOLA DE MINAS, 2018). Por possuir um modelo de ensino que promove a formação de Engenheiros Civis generalistas, com conhecimentos gerais de cada subárea de atuação profissional, tem seu foco distribuído em competências matemáticas, físicas e também nas cinco grandes subáreas da Engenharia Civil: Estruturas, Geotecnia, Recursos Hídricos, Transportes e Construção Civil.

Nos formulários foram propostos questionamentos que avaliam o quão proveitosas as atividades da graduação são para a vida profissional do estudante recém-formado, abordando perguntas acerca das metodologias de ensino utilizadas pelos professores da instituição, analisando a divisão de carga horária prática/teórica e verificando se são consideradas suficientes ou não para um bom ensino. Além disso, foi analisado a qualidade da estrutura de estudo disponibilizada aos estudantes e quão proveitosas são as atividades extracurriculares disponíveis na instituição. As questões apresentadas surgiram a partir da avaliação dos alunos membros do Grupo Civil Nota 5 que questionaram a influência da universidade no mercado de trabalho a partir das suas considerações de aspectos que seriam relevantes.

\subsection{Percepções da carga horária prática por discentes e egressos e a exigência no mercado de trabalho}

As aulas práticas além de desempenharem um papel fundamental na formação do aluno e na fixação do conteúdo a longo prazo, também são uma amostra da realidade do mercado de trabalho (AFONSO ALMEIDA, 2018). A partir disso, foi realizada uma pesquisa sobre a carga horária prática para alunos e egressos do curso, nos anos de 2017 e 2019.

Na avaliação feita com alunos em 2017, das 138 respostas, 53,0\% afirmaram não estarem satisfeitos com a carga horária de aulas práticas. É importante salientar que $10,1 \%$ não souberam opinar, o que remete que a porcentagem de satisfação foi realmente inferior. Em 2019, dos 183 alunos participantes da pesquisa, 66,1\% partilharam da mesma insatisfação.

Com o intuito de estabelecer bons parâmetros comparativos, o mesmo levantamento foi realizado com os egressos. Na pesquisa de 2017, dos 109 respondentes, 86,2\% se mostraram insatisfeitos com a carga horária prática do curso. E em 2019, de 98 avaliações de egressos, a insatisfação correspondeu a 89,8\%.

A fim de compreender a baixa satisfação apontada pelos egressos, foi abordado qual dos conhecimentos (dentre eles, o teórico, o prático e outros) é o mais exigido no mercado de trabalho. No ano de 2017, o conhecimento prático foi julgado como o mais requerido por $72,5 \%$ dos avaliados. Em 2019, a mesma opinião foi confirmada por 88,8\% dos participantes.

Logo, torna-se evidente que as opiniões referentes à insuficiência da carga horária de aulas práticas na estrutura do curso para alunos e egressos mantiveram-se elevadas tanto em 2017 quanto em 2019.

\subsection{Percepções do uso de softwares aplicativos por alunos e a exigência para egressos no mercado de trabalho}

O mercado de trabalho está cada vez mais em busca de profissionais capacitados em softwares aplicativos de natureza prática (SILVEIRA, 2004). Pensando nisso, com o intuito 
de avaliar o nível de utilização deles no referido curso, foi abordado também nos formulários aplicados a satisfação dos alunos e egressos relacionada a essa questão.

O nível de satisfação dos alunos com a utilização de softwares aplicativos foi avaliado baseado numa escala que variava de nulo ao excessivo. Dos 51 alunos do ciclo básico (alunos do segundo ao quarto período) que responderam em 2017, 43,4\% responderam que o nível de satisfação era moderado, 19,6\% como nulo e 33,3\% registraram como escasso o uso de softwares no ciclo básico. Já no ano de 2019, a pesquisa foi reaplicada nos alunos do ciclo básico, e registrou 63 respostas, das quais $44,4 \%$ dos discentes avaliaram como moderado o uso de programas e $22,2 \%$ como escasso.

Entretanto, a mesma pesquisa foi feita com o ciclo profissionalizante (alunos do quinto ao décimo período) no ano de 2017, e dos 137 discentes avaliados, 67,2\% responderam como escasso o uso de softwares. Pode-se perceber que dois anos depois a mesma concepção dos alunos manteve-se, visto que dos 120 alunos avaliados em 2019, 66,6\% informaram que foi escasso a utilização de softwares durante as disciplinas.

Com isso, é válido afirmar que a avaliação dos alunos do ciclo profissionalizante condiz com as necessidades do mercado de trabalho, já que no ano de 2019, dos 98 egressos avaliados, 67,3\% informaram que foi a competência mais exigida no mercado de trabalho.

\subsection{Percepções da metodologia do curso entre alunos e egressos}

A percepção de ensino para com o curso é muito particular, então busca-se obter respostas que exprimem uma opinião coletiva para avaliar o real estado do ensino e sua evolução ao longo do tempo. No entanto, objetiva-se analisar as opiniões mais aprofundadas por parte dos alunos e mais gerais por parte dos egressos, para se obter tanto a evolução do ensino da Engenharia Civil como para comparar como os egressos avaliam como um todo esse aspecto do curso.

Em 2017, o formulário aplicado aos egressos buscou estudar os dados de forma mais geral, uma vez que este abrange respostas de pessoas que se graduaram entre 2003 e 2017. Assim, a ideia seria que suas respostas fossem considerando o perfil de ensino da UFOP em Engenharia Civil nestes anos. Dentre os critérios gerais questionados, destaca-se "Qualidade dos Professores e Metodologia de Ensino", que das 109 respostas, para mais de 50,0\%, a qualidade dos professores é considerada boa. Enquanto a metodologia de ensino de forma geral é de regular para boa. Já em 2019 foi aplicado o mesmo formulário, com uma única diferença, que se trata da subdivisão das mesmas perguntas, especificando o ciclo básico e profissionalizante. Neste, obteve-se 98 respostas de egressos que colaram grau entre 1988 e 2019. Assim, para mais de 50,0\% dos egressos os professores do ciclo básico e a metodologia do ciclo básico e profissionalizante são de regular a bom, e os professores do ciclo profissionalizante são considerados de qualidade boa para ótima, por 72,0\%.

Para os discentes, os critérios foram mais específicos, sendo eles: "Didática, organização, domínio do conteúdo, conteúdos atualizados e interdisciplinaridade". Obtendo-se, em 2017, 212 respostas e em 2019 um total de 183 respostas para os tópicos estudados.

Assim, os alunos do segundo ao quarto período, em ambos os formulários, declararam uma satisfação de regular a boa para a maioria dos tópicos, com exceção de domínio do conteúdo e conteúdo atualizado, que foram avaliados entre bom e ótimo por 50,0\% em 2019, demonstrando uma avaliação positiva na qualidade de ensino no ciclo básico do curso.

Já entre os alunos do quinto ao sétimo período, notou-se que a maioria dos tópicos ficou entre regular e bom nos dois formulários, com exceção da interdisciplinaridade que se mostrou muito preocupante em 2017, uma vez que foi avaliada entre ruim para regular, em pelo menos 60,0\% das respostas, mas evoluiu para regular a bom, assim como domínio de conteúdo se destaca entre bom e ótimo em 2019. 
Tabela 1 - Porcentagens relativas à pergunta feita aos alunos do quinto ao sétimo período acerca da qualidade dos professores e a metodologia

\begin{tabular}{|c|c|c|c|c|c|c|}
\hline \multicolumn{7}{|c|}{ QUINTO AO SÉTIMO PERÍODO DE 2017} \\
\hline & PÉSSIMO & RUIM & REGULAR & BOM & ÓTIMO & $\begin{array}{l}\text { NÃO SEI } \\
\text { OPINAR }\end{array}$ \\
\hline Didática & $4,17 \%$ & $6,25 \%$ & $41,67 \%$ & $37,50 \%$ & $0,00 \%$ & $10,42 \%$ \\
\hline Organização & $2,08 \%$ & $2,08 \%$ & $43,75 \%$ & $37,50 \%$ & $2,08 \%$ & 12,50 \\
\hline $\begin{array}{c}\text { Domínio do } \\
\text { conteúdo }\end{array}$ & $0 \%$ & $0 \%$ & $22,92 \%$ & $47,92 \%$ & $18,75 \%$ & $10,40 \%$ \\
\hline Interdisciplinaridade & $2,08 \%$ & $25,00 \%$ & $35,42 \%$ & $20,83 \%$ & $4,17 \%$ & $12,50 \%$ \\
\hline $\begin{array}{c}\text { Conteúdos } \\
\text { atualizados }\end{array}$ & $0 \%$ & $18,75 \%$ & $41,67 \%$ & $22,91 \%$ & $4,17 \%$ & 12,50 \\
\hline \multicolumn{7}{|c|}{ QUINTO AO SÉTIMO PERÍODO DE 2019} \\
\hline & PÉSSIMO & RUIM & REGULAR & BOM & ÓTIMO & $\begin{array}{l}\text { NÃO SEI } \\
\text { OPINAR }\end{array}$ \\
\hline Didática & $2,33 \%$ & $18,60 \%$ & $46,51 \%$ & $26,74 \%$ & $4,65 \%$ & $1,17 \%$ \\
\hline Organização & $0 \%$ & $4,65 \%$ & $31,39 \%$ & $50,00 \%$ & $12,79 \%$ & $1,17 \%$ \\
\hline $\begin{array}{c}\text { Domínio do } \\
\text { conteúdo }\end{array}$ & $0 \%$ & $0 \%$ & $15,12 \%$ & $43,02 \%$ & $36,06 \%$ & $5,81 \%$ \\
\hline Interdisciplinaridade & $8,13 \%$ & $17,44 \%$ & $33,72 \%$ & $32,56 \%$ & $6,98 \%$ & $1,17 \%$ \\
\hline $\begin{array}{c}\text { Conteúdos } \\
\text { atualizados }\end{array}$ & $5,81 \%$ & $8,14 \%$ & $26,75 \%$ & $40,7 \%$ & $16,28 \%$ & $2,32 \%$ \\
\hline
\end{tabular}

Fonte: Elaborado pelos autores

Para os alunos do oitavo ao décimo período, um ponto bastante positivo foi o domínio do conteúdo, que foi avaliado de bom para ótimo. No entanto, destacaram-se negativamente interdisciplinaridade e conteúdo atualizado, que para mais de $60,0 \%$ das respostas estão entre ruim e bom. Os outros tópicos são considerados regulares.

Tabela 2 - Porcentagens relativas à pergunta feita aos alunos do oitavo ao décimo período acerca da qualidade dos professores e a metodologia

\begin{tabular}{|c|c|c|c|c|c|c|}
\hline \multicolumn{7}{|c|}{ OITAVO AO DÉCIMO PERÍODO DE 2017} \\
\hline & PÉSSIMO & RUIM & REGULAR & BOM & ÓTIMO & $\begin{array}{l}\text { NÃO SEI } \\
\text { OPINAR }\end{array}$ \\
\hline Didática & $4,44 \%$ & $14,44 \%$ & $30,00 \%$ & $40,00 \%$ & $4,44 \%$ & $6,67 \%$ \\
\hline Organização & $2,22 \%$ & $12,22 \%$ & $27,78 \%$ & $46,67 \%$ & $4,44 \%$ & $6,67 \%$ \\
\hline $\begin{array}{c}\text { Domínio do } \\
\text { conteúdo }\end{array}$ & $0 \%$ & $5,56 \%$ & $15,56 \%$ & $51,11 \%$ & $20,00 \%$ & $7,78 \%$ \\
\hline Interdisciplinaridade & $7,78 \%$ & $23,33 \%$ & $28,89 \%$ & $30,00 \%$ & $3,33 \%$ & $6,67 \%$ \\
\hline $\begin{array}{c}\text { Conteúdos } \\
\text { atualizados }\end{array}$ & $12,22 \%$ & $23,33 \%$ & $27,78 \%$ & $25,56 \%$ & $4,44 \%$ & $6,67 \%$ \\
\hline \multicolumn{7}{|c|}{ OITAVO AO DÉCIMO PERÍODO DE 2019} \\
\hline & PÉSSIMO & RUIM & REGULAR & BOM & óTIMO & $\begin{array}{l}\text { NÃO SEI } \\
\text { OPINAR }\end{array}$ \\
\hline Didática & $8,82 \%$ & $8,82 \%$ & $55,82 \%$ & $23,53 \%$ & $2,94 \%$ & $0 \%$ \\
\hline Organização & $5,88 \%$ & $11,76 \%$ & $32,35 \%$ & $44,18 \%$ & $5,88 \%$ & $0 \%$ \\
\hline $\begin{array}{c}\text { Domínio do } \\
\text { conteúdo }\end{array}$ & $5,88 \%$ & $5,88 \%$ & $14,70 \%$ & $50,00 \%$ & $23,53 \%$ & $0 \%$ \\
\hline Interdisciplinaridade & $11,76 \%$ & $29,41 \%$ & $29,41 \%$ & $26,47 \%$ & $2,94 \%$ & $0 \%$ \\
\hline $\begin{array}{c}\text { Conteúdos } \\
\text { atualizados }\end{array}$ & $5,88 \%$ & $17,65 \%$ & $55,88 \%$ & $20,6 \%$ & $0 \%$ & $0 \%$ \\
\hline
\end{tabular}

Fonte: Elaborado pelos autores 
Com isso é válido afirmar que, de acordo com a visão dos alunos, as disciplinas ofertadas pelo curso têm uma regularidade na maioria dos critérios que avaliam a qualidade do professor, o que demonstra um pensamento alinhado com egressos. Destacando-se positivamente, os professores do ciclo profissionalizante que são considerados de bom para ótimo, quanto a domínio de conteúdo. No entanto os tópicos de conteúdo atualizado e interdisciplinaridade demonstram escalas mais espaçadas entre ruim e boa, o que não constitui uma regularidade no período profissionalizante, fato é que demonstra um certo déficit destes aspectos metodológicos do curso.

\section{PERFIL DO ENGENHEIRO CIVIL FORMADO PELA INSTITUIÇÃO}

$\mathrm{Na}$ aplicação dos formulários de pesquisa aos alunos foi também solicitado que fosse respondido a respeito de qual estrutura pedagógica promove uma melhor formação dos alunos e se adequa melhor às exigências do mercado de trabalho atual na opinião e visão dos mesmos, já citado que a UFOP promove uma formação de Engenheiros Civis generalistas.

No formulário aplicado em 2017, dos 173 alunos matriculados no curso, distribuídos entre o segundo e o décimo períodos, 53,8\% responderam que a melhor estrutura pedagógica é a que forma engenheiros especialistas, com ênfase em alguma área de conhecimento específica ao final do curso. Contudo, quando se avalia os resultados de forma mais detalhada, separando os resultados por blocos de períodos, os resultados divergem entre os alunos do ciclo básico (segundo ao quarto período) e do ciclo profissionalizante (quinto ao décimo período). Os alunos do ciclo básico totalizaram 44 respostas, do quinto ao sétimo período, 43 respostas, e do oitavo ao décimo período foram 86 respostas, e suas respectivas avaliações encontram-se detalhadas na "Figura 1".

Em 2019, obteve-se 183 respostas dentre os alunos matriculados do primeiro ao décimo período. Em geral, dentre estas, obtém-se que a matriz curricular melhor avaliada para o engenheiro civil é a generalista, com 57,4\% dos votos. Detalhando-se os dados, os alunos do ciclo básico representam 63 respostas, do quinto ao sétimo período, 86 respostas, e do oitavo ao décimo período, 34 respostas, e suas avaliações encontram-se também na "Figura 1".

Figura 1 - Porcentagem de alunos que acreditam na formação do engenheiro civil generalista como ideal

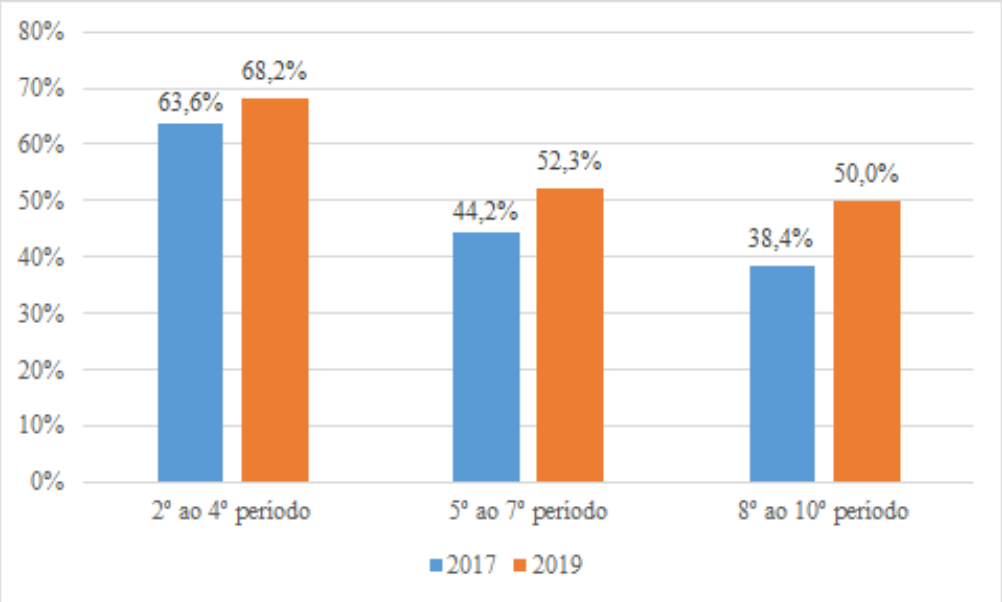

Fonte: Elaborado pelos autores

Da mesma forma foi feita a pesquisa com os ex-alunos. Das 109 respostas obtidas em 2017, 63,3\% acreditam e vivenciam que a melhor estrutura pedagógica é aquela que permite a 
formação do engenheiro generalista, com conhecimentos gerais em cada uma das subáreas de atuação profissional.

$\mathrm{Na}$ pesquisa feita em 2019 foram analisados os mesmos parâmetros de estrutura pedagógica. E obteve-se 98 respostas, em que 23,5\% destes se formaram após aplicação do formulário de 2017, sendo estas novas respostas o que favoreceu o comparativo entre os dois questionários de ex-alunos, bem como ajudou a construir melhor a visão dos egressos de Engenharia Civil da UFOP ao longo do tempo. Porém, da mesma forma que na pesquisa anterior, a análise dos egressos não saiu muito da média da última pesquisa, em que 62,2\% destes acreditam que a estrutura pedagógica generalista favorece o engenheiro a se adequar melhor ao mercado de trabalho.

O fato de os alunos do ciclo básico, em sua maioria, terem a mesma opinião dos já formados, corrobora com a ideia de que eles estão cientes daquilo que querem para o futuro, como também do que esperam do curso. Enquanto isso, os alunos do ciclo profissionalizante divergiram suas opiniões entre os formulários aplicados: em 2017 acreditavam que a formação em uma especialidade seria melhor para o mercado de trabalho, enquanto em 2019 se convenceram de que o engenheiro com formação generalista seria o ideal. Um dos motivos que pode ter auxiliado nessa mudança é o fato das atividades extracurriculares serem mais procuradas pelos alunos do ciclo profissionalizante, que os preparam para o futuro profissional, colocando-os em contato com o mercado de trabalho, pesquisas e outras ações sociais. Em 2017, de 136 alunos que responderam ao formulário do quinto ao décimo período, 23,5\% destes não participavam de nenhuma daquelas atividades, enquanto em 2019, de 120 estudantes, apenas 17,5\% não participavam delas. Quanto à análise das respostas dos egressos, essa é de extrema relevância visto que eles já se encontram atuando profissionalmente, e estatisticamente as opiniões permanecem as mesmas, em sua maioria concordam com uma melhor formação do engenheiro quando de forma generalista.

\section{ATIVIDADES EXTRACURRICULARES E SUA INFLUÊNCIA NO MERCADO DE TRABALHO}

Uma das maneiras de avaliar a qualificação dos discentes de Engenharia Civil da UFOP é o grau de engajamento destes em relação às atividades extracurriculares, que representam aquelas atividades realizadas para além da sala de aula referentes a habilidades e competências como forma de enriquecimento do aluno, promovendo melhorias em seus currículos somadas às experiências adquiridas (UNIVERSIA BRASIL, 2019).

No formulário aplicado aos alunos em 2017, de um total de 186 alunos, 30,1\% afirmaram não participar de nenhuma atividade extracurricular. Dos 70,0\% que participam de alguma atividade extracurricular, foi observado as três atividades com maior adesão entre os alunos, entre elas a Iniciação Científica, com 34,4\%, participação na Civil Jr. Consultoria (Empresa Júnior de Engenharia Civil), com 25,3\% e monitorias, com 13,4\%. Já no formulário aplicado em 2019, de um total de 183 alunos 36,6\% afirmaram não estar envolvidos com atividades extracurriculares, a Civil Jr. Consultoria teve uma adesão de 22,4\%, a Iniciação Científica com $18,6 \%$ e monitorias com 16,4\%. É válido destacar que muitos alunos podem ter participado de mais de uma atividade extracurricular durante a graduação, o que enquadra estas porcentagens como relativas e não exclusivas.

Dos 109 egressos respondentes ao formulário aplicado em 2017, 20,2\% afirmaram não terem participado de nenhuma atividade extracurricular durante a graduação. As atividades com maior adesão foram Iniciação Científica, com 49,5\%, monitorias, com 27,5\% e PET Civil (Programa de Educação Tutorial de Engenharia Civil) juntamente à Extensão, com 14,7\%. Para a mesma pergunta, feita em 2019, dos 98 egressos que responderam, 14,3\% não 
participaram de nenhuma das atividades, e entre aqueles que participaram, 43,9\% afirmaram fazer Iniciação Científica, 27,6\% responderam ter participado de monitorias e, $18,4 \%$ de projetos de Extensão.

Os alunos envolvidos com essas atividades avaliaram a importância de se participar das mesmas. Na pesquisa feita em 2017, 72,9\% consideraram muito importante, enquanto $2,15 \%$ consideraram nula. Já na pesquisa de 2019 , a relevância dessas atividades foi avaliada como muito grande por $58,5 \%$ das respostas e nula por $0 \%$ das respostas.

Os egressos foram questionados sobre a contribuição das atividades extracurriculares para o ingresso no mercado de trabalho e para as funções que exercem atualmente. Nos anos de 2017 e 2019, dentre os comentários mais recorrentes, destacam-se: "Direcionamento para área de atuação atual", "Melhoria nas habilidades de organização, responsabilidade, comunicação e trabalho em equipe", "Conhecimentos de gestão corporativa e empresarial", "Melhoria do currículo", "Aprendizagem de Softwares Aplicativos" e "Influência para a pósgraduação".

Dentre os discentes participantes, foi questionado acerca do respaldo dos professores e da universidade para essas atividades, podendo ser avaliados numa escala que varia entre nulo, escasso, moderado e suficiente. Em 2017, grande parte dos alunos que participam das atividades de Iniciação Científica, monitorias e PET Civil classificaram a assistência como moderada, enquanto participantes de outras atividades, como Civil Jr. Consultoria, CAEC (Centro Acadêmico de Engenharia Civil) e Projetos de Extensão classificaram como escasso. $\mathrm{Na}$ pesquisa de 2019, o respaldo foi tido como suficiente para Iniciação Científica e Monitorias, moderada para Civil Jr. Consultoria, PET Civil e Projetos de Extensão, e por fim, escassa para o CAEC.

A partir dessas análises, é possível notar que as atividades extracurriculares são tidas como relevantes devido à significativa avaliação dos alunos e reconhecimento dos egressos. Nota-se também que o respaldo possui maior destaque para as atividades relacionadas à pesquisa e ensino, como a Iniciação Científica e monitorias. Há de se reconhecer que houve melhorias para as atividades como Civil Jr. Consultoria e Projetos de Extensão, visto que em 2017 a assistência era tida como escassa e em 2019 evoluiu para moderada, enquanto o respaldo para o PET Civil persistiu como moderado. Com isso, verifica-se que ainda é necessário melhorar cada vez mais o apoio à estas atividades, visto que proporcionam importantes experiências e aprendizagens carregadas para o mercado de trabalho conforme avaliado pelos egressos.

\section{INFLUÊNCIA DO CURSO DE ENGENHARIA CIVIL DA UFOP NO MERCADO DE TRABALHO}

O curso de Engenharia Civil da UFOP busca manter contato direto dos alunos com o mercado de trabalho, facilitando a inserção do bacharel recém-formado no mesmo. Um dos objetivos da aplicação do formulário foi obter informações dos engenheiros civis já formados pela Universidade, buscando avaliar o quanto o conhecimento adquirido na graduação está sendo utilizado por eles nas áreas de atuação.

No formulário aplicado em 2017, de 100 respostas registradas, 31,0\% dos egressos avaliaram como 5 para a pergunta "Dentro da sua área de atuação, o quanto do conhecimento adquirido na graduação você aplicou ou aplica no seu trabalho? ", numa escala de 1 a 5 , onde 1 representava pouco e 5 muito, e $27 \%$ registraram como 3.

Em 2019, em uma aplicação semelhante obteve-se respostas direcionadas às áreas de atuação, podendo ser separadas em Construção Civil, Estruturas, Geotecnia, Hidráulica, Materiais de Construção, Saneamento e Transportes, utilizando os critérios de resposta como 
sendo pouco, regular e muito. Como pode-se perceber na "Figura 2" abaixo, houve grandes variações entre as áreas, o que pode ser justificado pela área de atuação de cada ex-aluno visto que, por exemplo, algo muito usado na área de Estruturas não é utilizado na mesma proporção em Saneamento. E vale ressaltar que a quantidade de respostas para cada área não se mantém, já que cada egresso respondeu respectivamente às suas áreas de atuação.

Figura 2 - Áreas de atuação no mercado de trabalho e grau de aplicação do aprendizado obtido na graduação

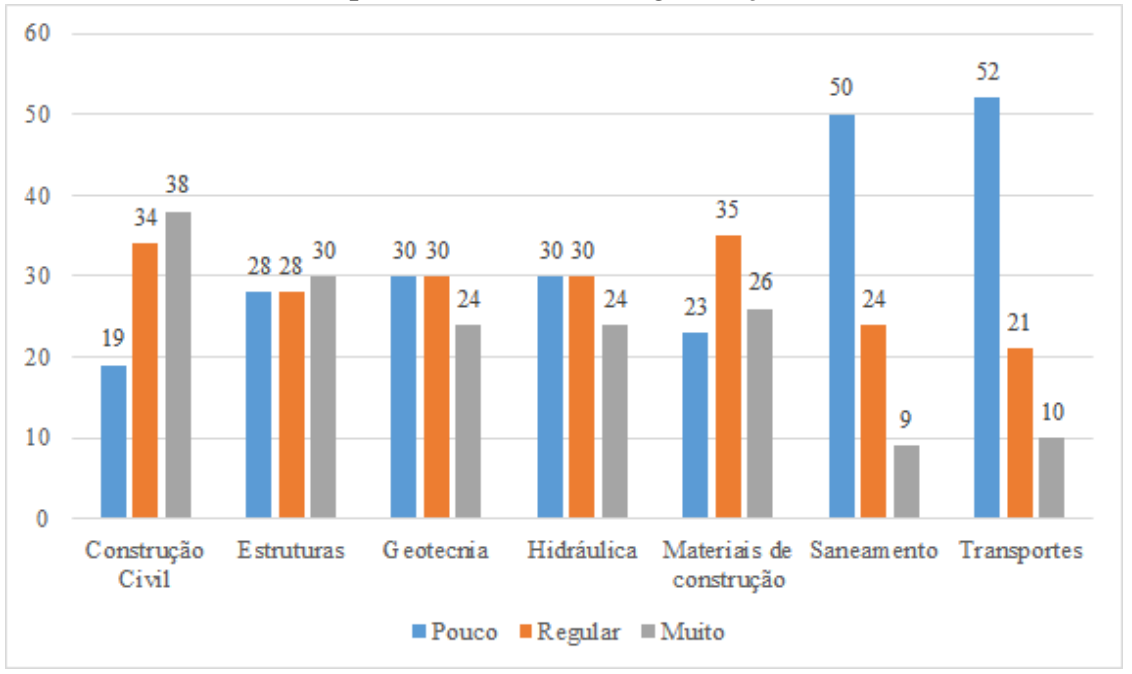

Fonte: Elaborado pelos autores

Outro ponto avaliado foi qual o grau de confiança que os alunos já formados apresentaram ao ingressarem no mercado de trabalho. Em 2017, de 109 respostas obtidas, $28,4 \%$ destes votaram na opção 3 , intermediária na avaliação. Outros $25,7 \%$ votaram na opção 1, se apresentando pouco confiantes.

Em contrapartida, em 2019, na mesma avaliação, com 98 respostas registradas, 37,8\% dos egressos marcaram um grau de confiança 3, enquanto $21,4 \%$ marcaram grau de confiança 4. Uma das possíveis explicações para esta mudança é a participação dos mesmos, enquanto discentes, em atividades extracurriculares, que pode ter ajudado a prepará-los melhor para a área de trabalho escolhida. Em 2017, de 109 avaliados, 79,8\% destes participaram de algum projeto extraclasse, enquanto em 2019, de 98 respostas, 85,7\% participaram.

Alguns critérios em relação ao curso também foram avaliados como à infraestrutura da instituição e qualidade dos alunos. Em 2017, os critérios foram avaliados como péssimo, ruim, regular, bom e excelente. Quanto à qualidade dos alunos, 56,9\% de um total de 109 respostas avaliaram como bom. E quanto à infraestrutura, incluindo bibliotecas, laboratórios e salas de aula, $62,4 \%$ avaliaram como bom.

Referente ao formulário aplicado em 2019, essa avaliação foi dividida em comprometimento dos alunos e estrutura da universidade e laboratórios, e foi utilizado o mesmo critério de avaliação do ano de 2017. Quanto ao comprometimento dos alunos, de 98 respostas obtidas, $51,0 \%$ avaliaram como regular. A estrutura da universidade se mantém na classificação, 60,2\% avaliaram como bom. E quanto aos laboratórios, 54,1\% afirmam ser bom. Com isso, percebeu-se o quão proveitoso pode ser o ambiente de estudo oferecido aos alunos, com uma boa estrutura e bons profissionais presentes.

Quanto a avaliação do mercado de trabalho com relação ao curso de Engenharia Civil da UFOP, em 2017, 41,3\% dos egressos avaliaram como Ótimo e 32,1\% como Bom, enquanto em 2019, 30,6\% dos egressos como ótimo e 56,1\% como bom. 
Um dos pontos avaliados nos questionários foi o nível de satisfação dos egressos com o curso de Engenharia Civil, de acordo com quanto o indicariam para outras pessoas. Portanto, com base no formulário de 2017, de 109 respostas, e na escala de 1 a 5, 58,7\% deles avaliaram como 5, 22,9\% indicaram como 4, enquanto 1,8\% avaliaram como 1 . Em 2019, de 98 respostas, 33,7\% avaliaram como 5, e 42,9\% registraram 4, enquanto 1,0\% indicou como 1. Assim verifica-se que cerca de $80,0 \%$ dos respondentes em ambas as pesquisas indicaria o curso de Engenharia civil da UFOP para outras pessoas.

\section{CONSIDERAÇÕES FINAIS}

Como proposto no trabalho, foi feita uma análise comparando a compatibilidade entre opiniões de alunos e ex-alunos da instituição avaliada. Com isso foi possível destacar os pontos apontados pelos alunos em relação a melhorias que podem ser implementadas no curso de Engenharia Civil da UFOP, assim como destacar os seus pontos positivos.

Um dos pontos mais frisados dos quatros formulários aplicados foi a necessidade de um aumento de carga horária de aulas práticas no curso, e atualização da metodologia de ensino, inserindo, por exemplo, utilização de softwares aplicativos e atualização do conteúdo teórico.

A partir da avaliação dos ex-alunos pôde-se perceber que, apesar das melhorias que necessitam ser feitas, a instituição é bem avaliada no mercado de trabalho pela qualidade dos engenheiros civis formados por ela, e pela estrutura que é oferecida aos mesmos.

Para oferecer melhorias ao curso, as análises contidas neste documento serão utilizadas como apoio ao NDE (Núcleo Docente Estruturante). Algumas destas já vêm acontecendo com a participação do grupo Civil Nota 5, como a reformulação da matriz curricular, a fim de atender às atuais necessidades dos alunos e futuros engenheiros no mercado de trabalho.

\section{Agradecimentos}

Ao professor Jaime Martins, por ser orientador do projeto Civil Nota 5 e o professor Fernando Abecê, por ser co-orientador deste projeto.

Ao NDE, em especial aos professores Adilson Leite e Walliston Fernandes pelo apoio.

Aos antigos e atuais integrantes do Civil Nota 5, que formularam os questionários.

Ao tradutor Matheus Veloso e à corretora Elisa Lanna pela prestatividade.

\section{REFERÊNCIAS}

ALMEIDA, Afonso. Por que você precisa de aulas práticas na Universidade? 2018. Disponível em: https://portal.unigranrio.edu.br/blog/por-que-voce-precisa-de-aulas-praticasna-universidade. Acesso em: 27 maio 2020.

ESCOLA DE MINAS, UNIVERSIDADE FEDERAL DE OURO PRETO. Engenharia Civil. 2018. Disponível em: https://www.em.ufop.br/files/matrizCIV22018_1.pdf. Acesso em: 14 maio 2020.

MEC. Detalhes do Curso - (586) Bacharelado em Engenharia Civil. 2020. Disponível em: http://emec.mec.gov.br/emec/consultacadastro/detalhamento/d96957f455f6405d14c6542552b0f6eb/Ng==/c1b85ea4d704f246bcced 664fdaeddb6/RU5HRU5IQVJJQSBDSVZJTA==. Acesso em: 06 maio 2020. 
"Os desafios para formar hoje o engenheiro do amanhã"

MENDES, Vitor Freitas et al. Análise do curso de Engenharia Civil da Universidade Federal de Ouro Preto de acordo com a percepção dos alunos. In: ENGENHARIA do Século XXI. Belo Horizonte: Ed. Poisson, 2019. Cap. 6. p. 54-62. Disponível em: https://www.poisson.com.br/livros/engenharia/volume1/. Acesso em: 06 maio 2020

SILVEIRA, Sérgio Amadeu da. Software livre: a luta pela liberdade do conhecimento. 2004. Disponível em: https://www.ufrgs.br/soft-livre-edu/arquivos/amadeu-livro-softlivre.pdf. Acesso em: 27 mar. 2020.

UNIVERSIA BRASIL. O que são atividades extracurriculares e como usá-las em seu currículo. 2019. Disponível em:

https://noticias.universia.com.br/emprego/noticia/2013/01/03/981669/4-atividadesextracurriculares-vo-melhorar-seu-curriculo.html. Acesso em: 27 maio 2020.

\title{
ANALYSIS OF THE CIVIL ENGINEERING COURSE FROM UNIVERSIDADE FEDERAL DE OURO PRETO AND ITS ADAPTATION TO THE JOB MARKET
}

\begin{abstract}
With the teaching and learning process gaining prominence in the job market, sought to glimpse through forms the influence of the curriculum matrix on the performance of the trained professional, in addition to comparing the opinions of students and alumni of the institution, in order to assess how satisfied they are with the course model offered. This work has a dissertative-argumentative character, whose objective is to interpret the data obtained and apply improvements to the Civil Engineering course at the Federal University of Ouro Preto (UFOP), such as increasing the practical workload and updating teaching methodologies.
\end{abstract}

Keywords: Teaching quality. Civil Engineering. Students. Egresser. Job Market. 